\title{
3
}

\section{Supported Decision-Making: A Good Idea in Principle but We Need to Consider Supporting Decisions about Voluntary Assisted Dying}

\author{
Nola M Ries and Elise Mansfield ${ }^{1}$
}

\section{Introduction}

Australia has an ageing population and many older people will, at some point, experience an injury, such as a stroke, or develop a condition, like Alzheimer's disease, that results in impaired cognitive functioning. Alzheimer's disease is one of many dementia syndrome diseases characterised by impairments in memory, thinking, perception and language skills. ${ }^{2}$ Dementia currently affects one out of ten adults over the age of 65 and three out of ten over age $85 .{ }^{3}$ Each day in Australia, around

\footnotetext{
1 This research was funded by the National Health and Medical Research Council via a Dementia Research Team Grant (APP1095078). This research was also supported by infrastructure funding from the Hunter Medical Research Institute. The authors would like to thank Sandra Dowley, Max Katz-Barber and Lucy Boyd for assistance with data collection.

2 'Dementia', Australian Institute of Health and Welfare (Web Page) <http://www.aihw.gov.au/ dementia/>.

3 Australia Bureau of Statistics, 'Dementia and Death in Australia', Causes of Death, Australia, 2015 (Catalogue No 3303.0, 26 July 2017) <https:/www.abs.gov.au/ausstats/abs@.nsf/Lookup/ by\%20Subject/3303.0 2015 -Main\%20Features Dementia - 10002>.
} 
100 stroke events occur. Nearly 400,000 people across the country have had a stroke and over a third report disabling sequelae, including problems with thinking and communication. ${ }^{4}$ People living with impaired cognition may experience difficulties in making decisions across a range of domains, including medical, financial and other personal domains.

Laws, such as 'guardianship' Acts, allow substitute decision-makers to be appointed and given the legal authority to make choices and manage the affairs for a person who is judged to lack decisional capacity. In principle, substitute decision-makers are expected to make decisions that reflect the will and preferences of the incompetent person (that is, to make the decision the person would make if they had capacity) or, if they are uncertain what the person would want, to act in the best interests of that person. In practice, a substitute decision-maker's knowledge of the person's preferences may be 'only slightly better than chance's and many decision-makers report significant psychological burden in carrying out their role.

Laws based on guardianship and substitute decision-making models are increasingly criticised for perpetuating rigid notions of capacity as an 'all-or-nothing' concept and disempowering people who experience impaired capacity. Internationally and domestically, a major legal and policy shift is underway to adopt models of supported decision-making. This model is based on the premise that all people have the right to make decisions for themselves and people with cognitive impairments should receive appropriate supports to maximise their decisional capacity. These principles are articulated in the United Nations (UN) Convention on the Rights of Persons with Disabilities ${ }^{6}$ and adopted by the Australian Law Reform Commission in its influential 2014 report, Equality, Capacity and Disability in Commonwealth Laws. ${ }^{7}$

4 Australian Institute of Health and Welfare, Australia's Health 2016 (Australia's Health Series no 15, Catalogue no AUS 199, 2016) ch 3.6 ('Stroke') <https://www.aihw.gov.au/reports/australiashealth/australias-health-2016/contents/summary>; Australia Bureau of Statistics, 'Stroke', Profiles of Disability, Australia, 2009 (Catalogue No 4429.0, 27 June 2012) <http://www.abs.gov.au/ausstats/ abs@.nsf/Lookup/4429.0main+features100262009>.

5 Lauren G Collins, Susan M Parks and Laraine Winter, 'The State of Advance Care Planning: One Decade After SUPPORT' (2006) 23(5) American Journal of Hospice and Palliative Medicine 378, 379; David I Shalowitz, Elizabeth Garrett-Mayer and David Wendler, 'The Accuracy of Surrogate Decision Makers: A Systematic Review' (2006) 166(5) Archives of Internal Medicine 493.

6 Convention on the Rights of Persons with Disabilities, opened for signature 13 December 2006, 2515 UNTS 3 (entered into force 3 May 2008).

7 Australian Law Reform Commission, Equality, Capacity and Disability in Commonwealth Laws (ALRC Report 124, 24 November 2014). 
Governments across Australia are engaged in supported decision-making reform initiatives. Victoria amended its Powers of Attorney Act 2014 and Medical Treatment Planning and Decisions Act 2016 to recognise a 'supportive attorney' to assist with financial and personal decisions and a 'support person' for medical treatment decisions. ${ }^{8}$ A person who anticipates a need for assistance with decision-making may appoint supporters whose role is to help the person understand their options and make and implement choices. In New South Wales, a 2018 Law Reform Commission review recommended replacing the state's decadesold Guardianship Act 1987 with a new Assisted Decision-Making Act that would formally recognise supported decision-making. ${ }^{9}$

At the same time, voluntary assisted dying (VAD) is also an area of law reform activity. Victoria's Voluntary Assisted Dying Act 2017 took effect in June 2019 and Western Australia's VAD legislation will come into force in mid-2021. Other states and territories have undertaken inquiries into legalisation of VAD and various bills have been introduced to seek legislative change. ${ }^{10}$

Laws for supported decision-making and VAD are both championed as promoting autonomy, dignity and rights to self-determination. Supported decision-making focuses on empowering people living with a disability to make or communicate decisions about their lives. VAD focuses on empowering people, typically those with advanced serious illness, to control the timing and manner of their death. Despite being grounded in shared principles and aims, there has been little attention to date on formal mechanisms of supported decision-making in the end-oflife context generally and VAD in particular.

Even aside from the contentious area of VAD, an Australian legal expert on disability rights and supported decision-making has criticised the 'minimal research to date on the practical implementation of supported

8 'Enduring Power of Attorney', Office of the Public Advocate (Web Page) <http://www.public advocate.vic.gov.au/power-of-attorney/supportive-attorney-appointments $>$.

9 NSW Law Reform Commission, Review of the Guardianship Act 1987 (Report 145, 21 May 2018) ('NSW Law Reform Commission Report').

10 In March 2021, the Parliament of Tasmania passed the End of Life Choices (Voluntary Assisted Dying) Bill 2020, with implementation to follow: <https://www.parliament.tas.gov.au/Bills/ Bills2020/30_of_2020.html>. In May 2021, the Voluntary Assisted Dying Bill 2021 was introduced in the Queensland Parliament: <https://www.health.qld.gov.au/system-governance/legislation/voluntaryassisted-dying-bill>. For an overview of legislative reform efforts in this area, see Ben White and Lindy Willmott, 'Future of Assisted Dying Reform in Australia' (2018) 42 Australian Health Review 616. 
decision-making', emphasising that ' $\mathrm{t}] \mathrm{he}$ issues at stake for people with cognitive and psychosocial disabilities and the public interest are too significant and potentially grave to be decided ... [without] careful' study. ${ }^{11}$ Similarly, Douglas and Bigby observe that there is 'little evidence about the practice of support or [its] essential ingredients' ${ }^{12}$ to ensure the will and preferences of persons with disability are at the centre of decisions that affect them. Where projects have been undertaken, they have mostly focused on younger people with intellectual disability and strategies to help them gain more confidence in areas such as money management and living independently. ${ }^{13}$ In such contexts, the aim of supported decisionmaking is to enhance participation and integration into the community and enhance life satisfaction. ${ }^{14}$ Supporting decision-making to access medical assistance to die is somewhat outside these typical objectives and raises new issues for consideration.

With further law reforms on supported decision-making and VAD anticipated in Australia, it is timely to advance the empirical research base on formal supporter arrangements and to consider how people with serious illness and decision-making impairments can be supported in the context of decisions about accessing VAD. These are the key topics this chapter addresses. First, the chapter reports on a New South Wales survey that investigated the views of community members in a health service setting on supported decision-making. The survey was undertaken during the NSW Law Reform Commission's review of the Guardianship Act 1987, which provided an opportunity to elicit community opinions on a formal system of supported decision-making recognised by law. Second, the chapter considers supported decision-making in the context of VAD, drawing on the survey findings and literature to consider the needs of people seeking assistance with decision-making, formal (and informal)

11 Terry Carney and Fleur Beaupert, 'Public and Private Bricolage - Challenges Balancing Law, Services and Civil Society in Advancing CRPD Supported Decision-Making' (2013) 36(1) University of New South Wales Law Journal 175, 199.

12 Jacinta Douglas and Christine Bigby, 'Development of an Evidence-Based Practice Framework to Guide Decision Making Support for People with Cognitive Impairment due to Acquired Brain Injury or Intellectual Disability' (2018) 42(3) Disability and Rehabilitation 434.

13 See eg, projects summarised in Anna Arstein-Kerslake et al, 'Future Directions in Supported Decision-Making' (2017) 37(1) Disability Studies Quarterly 1.

14 These aims are reflected in outcome measures recommended for supported decision-making programs: Karrie A Shogren and Michael L Wehmeyer, 'A Framework for Research and Intervention Design in Supported Decision-making' (2015) 3(1) Inclusion 17. 
supporters and clinicians. As the intersection of supported decisionmaking and VAD is a novel and fraught area, the paper proposes areas for future research.

\section{The survey study}

\section{Participant eligibility and recruitment}

A survey study was designed to seek the views of community members on the impacts of chronic illness on people's lives. The questions on supported decision-making, discussed in detail below, were a module within this chronic illness survey. ${ }^{15}$ The study involved people attending outpatient clinics at a major tertiary referral hospital in regional New South Wales, Australia. ${ }^{16}$ Eligible participants for the survey were aged 18 years and older, either a patient attending the clinic for a medical appointment or a person accompanying the patient, English-speaking, able to provide informed consent, and mentally and physically well enough to complete a touchscreen survey.

An information statement about the study was displayed at the clinic reception. A trained research assistant approached people in the waiting area to check their eligibility and interest in doing the survey. Consent was confirmed by undertaking the survey. The survey was completed on an iPad and took approximately 10 minutes to complete. The research assistant recorded the gender and age group of individuals who declined to participate in the survey. Data were collected in September and October 2017.

\section{Survey questions on supported decision-making}

The survey module on supported decision-making provided the following background information:

15 Other modules in the survey investigated knowledge and attitudes about chronic diseases. It is important to note that the survey respondents were not prompted to consider supported decisionmaking in the context of end-of-life decisions generally or VAD in particular.

16 Ethics approval for the study was obtained from the Hunter New England Health Human Research Ethics Committee (17/03/15/4.06) and the University of Newcastle Human Research Ethics Committee (H-2017-0146). 
Some conditions may affect peoples' ability to make important decisions on their own. A law may be passed to allow people to legally appoint a formal supporter to help them make decisions. For example, the formal supporter might attend appointments with the person, or help them understand their options.

With this context in mind, respondents were asked to answer questions by indicating their level of agreement with given response options on a four-point Likert scale (strongly agree, agree, disagree, strongly disagree). Some questions included 'unsure' or 'not applicable' response options, as noted in Tables 1 and 2 .

Survey respondents were first asked to indicate their level of agreement with the statement that allowing people to legally appoint a formal supporter is a good idea. They were then asked to indicate their level of agreement with specified benefits and downsides of supported decision-making.

Having a formal supporter would allow me to: (1) Still make my own decisions; (2) Be more confident that I was making the right decisions; (3) Have my wishes respected; and (4) Worry less about being taken advantage of.

I would be worried that a formal supporter may: (1) Not be trustworthy; (2) Not have the time to help me; (3) Cost me money; (4) Try to get me to make the decisions they want; (5) Have disagreements with me; (6) Not know when I need them to help me.

Last, respondents were asked to indicate their level of agreement as to whom they would appoint as their formal supporter, with the following options presented: my wife/husband/partner; my adult child/children; another family member; a friend; a community volunteer; a care worker/ disability services worker; a lawyer.

\section{Survey results}

A total of 408 people were approached. Of these, 17 were ineligible. A further 21 were called into their appointment before they were asked for consent. Of the remaining 370 eligible individuals, 250 consented to participate (consent rate of 68 per cent). There was no significant difference in gender between people who consented and did not consent to participate $(p=0.18)$. However, people aged $65-74$ years were significantly 
less likely to consent compared to other age groups $(p=0.045)$. Sixty-five people who consented to participate were removed from the dataset as they did not provide complete data for at least one item, leaving 185 participants available for analysis. ${ }^{17}$ Participants' average age was 56 years ( $\mathrm{SD}=17$ years), and there were approximately equal numbers of each gender (48 per cent male, $n=89$ ).

\section{Is a formal system of supported decision-making a good idea?}

There was nearly universal agreement among survey respondents that allowing people to legally appoint a formal supporter is a good idea: of the 185 respondents who answered this question, 95 per cent $(n=176)$ of respondents either agreed (66 per cent, $n=122$ ) or strongly agreed (29 per cent, $n=54)$. Just 3 per cent of respondents $(n=5)$ expressed disagreement and 2 per cent $(n=4)$ were unsure.

\section{Perceived benefits and downsides of having a formal supporter}

As reported in Table 1, a substantial majority of respondents (87-96 per cent) agreed that having a formally appointed supporter would enable them to continue to exercise decision-making autonomy and self-determination.

Table 1. Perceived benefits of a formally appointed supporter $(n=180)$

\begin{tabular}{|l|c|}
\hline A formal supporter would allow me to: & Agreement (n) \\
\hline Have my wishes respected & $96 \%(172)$ \\
\hline Be more confident that I was making the right decisions & $90 \%(162)$ \\
\hline Worry less about being taken advantage of & $90 \%(162)$ \\
\hline Still make my own decisions & $87 \%(156)$ \\
\hline
\end{tabular}

Source: Authors' summary of survey results.

Table 2. Perceived downsides of a formally appointed supporter $(n=173)$

\begin{tabular}{|l|c|}
\hline I would be worried that a formal supporter may: & Agreement (n) \\
\hline Have disagreements with me & $73 \%(125)$ \\
\hline Not know when I need them to help me & $66 \%(115)$ \\
\hline Try to get me to make the decisions they want & $58 \%(101)$ \\
\hline
\end{tabular}

17 Frequencies and proportions are calculated based on the number of responses available for each question. These may total less than 185 due to missing data (eg where participants skipped questions). 


\begin{tabular}{|l|c|}
\hline I would be worried that a formal supporter may: & Agreement (n) \\
\hline Not have the time to help me & $56 \%(97)$ \\
\hline Cost me money & $54 \%(93)$ \\
\hline Not be trustworthy & $53 \%(92)$ \\
\hline
\end{tabular}

Source: Authors' summary of survey results.

There was less unanimity in respondents' perceptions of the downsides of having a formally appointed supporter, as reported in Table 2. Respondents had divided views on potential areas of concern, such as the trustworthiness of a supporter and their availability to perform their role. However, nearly three-quarters of respondents ( 73 per cent, $n=125$ ) would worry about disagreements with their supporter and around two-thirds (67 per cent, $n=115$ ) were concerned the supporter might not know when they should help. Over half of respondents (58 per cent, $n=101)$ were worried about coercion from their supporter.

\section{Preferred person to appoint as a supporter}

When asked who they would appoint as their formal supporter, a majority of respondents agreed or strongly agreed they would choose their spouse/ partner (84 per cent, $n=144$ ), their adult child (81 per cent, $n=138$ ) or another family member (64 per cent, $n=110)$. Around half would choose a lawyer (56 per cent, $n=96$ ), a care or disability services worker (50 per cent, $n=85$ ) or a friend ( 49 per cent, $n=84$ ). A community volunteer was the least popular option, with only 30 per cent $(n=52)$ of respondents expressing agreement with this option. Around 10 per cent of respondents selected 'not applicable' for the spouse/partner and adult child response options ( 12 per cent, $n=21$, and 9 per cent, $n=16$, respectively), indicating they may not have such people in their lives.

\section{Discussion}

\section{Supported decision-making: A good idea in principle and considerations for VAD}

An important finding from this survey is that nearly all respondents thought legal recognition of supported decision-making is a good idea. Law reforms to allow formal supporter appointments therefore appear to accord with community views. Moreover, there was substantial 
agreement (87-96 per cent) with the benefits of supported decisionmaking in enabling people to make and have confidence in their own decisions, have their choices respected and worry less about others taking advantage of them. The areas the survey identified as being of concern having disagreements and not knowing when the person with a disability might need support - highlight that supported decision-making is a relational process that needs its own supports. People who choose to enter formal supporter agreements need guidance on identifying their needs, communicating effectively and resolving disputes. Supporters must understand and act in their role as a supporter, not as someone who takes over and substitutes their values and preferences for that of the person living with cognitive impairment.

These findings provide a foundation for identifying and discussing specific considerations in relation to supported decision-making and VAD. Effective support for decision-making is an area for attention in highquality end-of-life care, including support for VAD decisions, where this option is among the legally available choices. For people with advanced serious illness, maintaining control, dignity and self-respect are identified as factors that improve their dying and death experience. ${ }^{18}$ Moreover, in the end-of-life context, being free from coercion is vital to a voluntary choice to access medical assistance to die.

\section{Capacity and the level of support required}

Issues of decision-making capacity are central to both supported decisionmaking and VAD. A person who wishes to appoint a formal supporter must have the capacity to do so; ${ }^{19}$ for instance, they must be able to understand the nature and effect of making such an appointment. Since formal support arrangements are targeted for people with cognitive disability, ascertaining decision-making capacity will typically be an important part of the process. Once a supporter appointment is in place, the individual in the role is responsible for enhancing the decision-making capacity of the person with a disability. They may do so by gathering and explaining information relevant to a decision, accompanying the person to appointments with service providers to help ask questions and weigh up options.

18 Lois Downey et al, 'The Quality of Dying and Death Questionnaire (QODD): Empirical Domains and Theoretical Perspectives' (2009) 39(1) Journal of Pain and Symptom Management 9.

19 See eg, Victoria's Medical Treatment Planning and Decisions Act 2016 s 31(1). 
Restricting access to VAD for adults with capacity to make their own choice on the matter is an important legislative safeguard. ${ }^{20}$ This raises the question of whether a person who requires decision-making support is an eligible person to access VAD. Victoria's Voluntary Assisted Dying Act 2017 makes it clear that 'a person has decision-making capacity to make a decision if it is possible for the person to make a decision with practicable and appropriate support'. ${ }^{21}$ A 2018 Western Australian parliamentary inquiry into end-of-life choices stated:

Consistent with the United Nations Convention on the Rights of Persons with Disabilities (to which Australia is a signatory) individuals with a disability must be afforded the same legal rights as the rest of the community. ${ }^{22}$

The inquiry cited submissions from People with Disabilities WA and the Australian Federation of Disability Organisations advocating that everyone has 'the right to be supported in making properly informed decisions about their medical treatment'. ${ }^{23}$ Western Australia's Voluntary Assisted Dying Act 2019 adopts this language, stating:

a person has the right to be supported in making informed decisions about the person's medical treatment, and should be given, in a manner the person understands, information about medical treatment options including comfort and palliative care and treatment. ${ }^{24}$

Further, the legislation encourages people to 'openly discuss death and dying' 25 and states that 'a person should be supported in conversations with the person's health practitioners, family and carers and community about treatment and care preferences. ${ }^{26}$

\footnotetext{
20 For discussion, see eg, Carmelle Peisah, Linda Sheahan and Ben White, 'Biggest Decision of Them All - Death and Assisted Dying: Capacity Assessments and Undue Influence Screening' (2019) 49(6) Internal Medicine Journal 792.

21 Voluntary Assisted Dying Act 2017 (Vic) s 4(4)(d).

22 Joint Select Committee on End of Life Choices, Parliament of Western Australia, My Life, My Choice: The Report of the Joint Select Committee on End of Life Choices (Report 1, August 2018) 221, <http:// www.parliament.wa.gov.au/parliament/commit.nsf/(Report+Lookup+by+Com+ID)/71C9AFECD 0FAEE6E482582F200037B37/\$file/Joint+Select+Committe+on+the+End+of+Life+Choices+-Report+for+Website.pdf $>$.

23 Ibid 222.

24 Voluntary Assisted Dying Act 2019 (WA) s 4(1)(c).

$25 \operatorname{Ibids} 4(1)(\mathrm{f})$.

$26 \operatorname{Ibid} \mathrm{s} 4(1)(\mathrm{g})$.
} 
Recent inquiries into VAD in other Australian jurisdictions also recognise that people with disabilities must not be discriminated against, implying that, with appropriate supports, individuals with cognitive disability can be enabled to make choices about VAD. For example, the Australian Psychological Society takes the view that supported decision-making can be appropriate in the context of VAD choices:

People with a disability should be provided with appropriate support to make decisions, and having a disability does not negate their right to assisted dying or any other service that is legal for non-disabled persons. ${ }^{27}$

In its 2018 review of guardianship legislation, the NSW Law Reform Commission recommended that a new Assisted Decision-Making Act should provide that 'if a person ... has decision-making ability in relation to a healthcare decision only when assisted by the supporter, the person has decision-making ability for the purposes of [the law]'. ${ }^{28}$

The ways in which capacity is understood and applied in the VAD context may, however, undermine the principle of non-discrimination. An analysis of submissions to a UK commission on assisted dying found:

[a] tendency towards a conceptual and clinical shift toward a presumption of incapacity. This appeared to be based on the belief that assisted suicide should only be open to those with a high degree of mental capacity to make the decision. ${ }^{29}$

In contrast, early commentary on supported decision-making argued:

The starting point is not a test of capacity, but the presumption that every human being is communicating all the time and that this communication will include preferences. Preferences can be built up into expressions of choice and these into formal decisions.

27 Australian Psychological Society, Submission to the Inquiry into End of Life Choices in the ACT (March 2018) <https://psychology.org.au/getmedia/bc8fd1fb-d944-4d2e-8f64-d70445e8de5c/APSSubmission-ACT-Inquiry-into-end-of-life-choices.pdf>.

28 NSW Law Reform Commission Report (n 9) 157.

29 Annabel Price et al, 'Concepts of Mental Capacity for Patients Requesting Assisted Suicide: A Qualitative Analysis of Expert Evidence Presented to the Commission on Assisted Dying' (2014) 15(32) BMC Medical Ethics 1 (emphasis added). 
From this perspective, where someone lands on a continuum of capacity is not half as important as the amount and type of support they get to build preferences into choices. ${ }^{30}$

An Irish study of psychologists' views and experiences of supported decision-making also revealed that the legal presumption of capacity is undermined by a 'culture of incapacity' that is embedded in attitudes and practices. ${ }^{31}$ European bioethics experts echoed concern that the bar [for decision-making capacity] is sometimes set too high' for people seeking access to VAD. ${ }^{32}$ They contend:

Any doctor who attempts to prevent a patient who is mentally competent from accessing assisted suicide is adopting an overpaternalistic stance that is contrary to the more general emphasis on autonomy in biomedical ethics. One might never choose assisted suicide for oneself or might think that the practice itself is deeply unethical, but to impose those values on one's patients is deeply unethical and unprofessional..$^{33}$

\section{Decision-making domains: Complex or 'high-risk' decisions}

There has been some discussion as to whether certain domains of decisionmaking, such as significant financial decisions, should be excluded from the scope of formal supported decision-making arrangements. In the NSW review of the Guardianship Act 1987, several stakeholders suggested that people with cognitive disability are at heightened vulnerability to financial exploitation and that appointed supporters should not assist with major financial decisions. ${ }^{34}$ The Law Reform Commission rejected such a restriction, arguing instead that if supported decision-making laws exclude support for particular kinds of decisions then support for such

30 Stephanie Beamer and Mark Brookes, Making Decisions: Best Practice and New Ideas for Supporting People with High Support Needs to Make Decisions (Values into Action, 2001) 4, cited in Arstein-Kerslake et al (n 13).

31 E Rogers et al, 'Psychologists' Perspectives on Supported Decision Making in Ireland' (2020) 64(3) Journal of Intellectual Disability Research 234.

32 David Shaw, Manuel Trachsel and Bernice Elger, 'Assessment of Decision-Making Capacity in Patients Requesting Assisted Suicide' (2018) 213(1) British Journal of Psychiatry 393, 394.

33 Ibid.

34 NSWLaw Reform Commission Report (n 9) 82, citing submissions: NSW Disability Network Forum, Submission GA39 (25 January 2017) 11; Royal Australian and New Zealand College of Psychiatrists NSW Branch, Submission GA53 (31 January 2017) 2-3; Seniors Rights Service, Submission GA61 (31 January 2017) 14. 
decisions would occur on an informal basis, outside the safeguards in the law. ${ }^{35}$ Moreover, the commission felt that complex areas of decisionmaking are precisely the areas where support should be available.

By analogy, formal support for understanding VAD and making end-oflife care decisions may also be desirable and would ensure that safeguards both in VAD laws and supported decision-making rules are available. Ultimately, it is contended that supported decision-making recognises that adults, including those in formal supporter arrangements, 'have the right to make decisions, including the right to make risky or "bad" decisions. ${ }^{36}$ At the same time, it is not a straightforward process to support decision-making in difficult situations where the decision may pose some harm to the individual'. ${ }^{37}$ Supporters report being more riskaverse in such circumstances and prioritising protection from harm over promotion of autonomy. ${ }^{38}$ The issue of supporting VAD decision-making will run up against persistent debates about the harms of hastening death and whether choosing assistance to die is in a person's best interests. ${ }^{39}$

\section{Eligibility to be a supporter}

In Australia, law reform discussions on supported decision-making have generally favoured wide latitude in who is eligible to be a formally appointed supporter to assist with health-related decisions. ${ }^{40}$ In its recommendations for a new Assisted Decision-Making Act, the NSW Law Reform Commission stated: 'we want to provide people looking for support with as many options as possible to suit their circumstances'. ${ }^{41}$

\footnotetext{
35 A person making a support agreement can, however, choose to exclude certain matters from their arrangement with an appointed supporter.

36 NSW Law Reform Commission Report (n 9) 19.

37 Arstein-Kerslake et al (n 13).

38 See Rogers et al (n 31); Christine Bigby, Mary Whiteside and Jacinta Douglas, 'Providing Support for Decision Making to Adults with Intellectual Disability: Perspectives of Family Members and Workers in Disability Support Services' (2019) 44(4) Journal of Intellectual \& Developmental Disability 396.

39 See eg, James Downar, 'Is Physician-Assisted Death in Anyone's Best Interest? Yes.' (2015) 61(4) Canadian Family Physician 314; and Edward T St Godard, 'Is Physician-Assisted Death in Anyone's Best Interest? No.' (2015) 61(4) Canadian Family Physician 316.

40 Other requirements may apply for supporters who assist with financial decisions. Under Victoria's Powers of Attorney Act 2014 and the NSW recommendations, if an appointee is to support financial decision-making, they must not have prior bankruptcy or conviction for a dishonesty offence unless this has been acknowledged in the support agreement.

41 NSW Law Reform Commission Report (n 9) 74 [7.29].
} 
Under Victoria’s Medical Treatment Planning and Decisions Act 2016 and the NSW recommendations, a person under age 18 may be appointed as a supporter provided they understand the role and its responsibilities. ${ }^{42}$

Our survey respondents identified people within their family network as their preferred supporters, while community volunteers were their least preferred option. However, investing resources in volunteer programs may be vital to provide access to supported decision-making for people who are socially isolated or otherwise do not have relatives or friends able to assist them in a supporter arrangement. ${ }^{43}$ To this end, a Victorian pilot project matched people with mild intellectual disability with a trained volunteer to assist them with decision-making. It was found that success depended on 'skilled volunteers who were committed to spending many months developing a relationship with participants and persevering through many barriers when supporting them to make and act on their own decisions. ${ }^{44}$

This finding highlights that a community volunteer model may be poorly suited to VAD decision-making if legislation (or practice) restricts access to terminally ill people with a limited life expectancy. A short time period of only months of life may be insufficient for a volunteer to establish a relationship with the person to support them in decision-making about VAD. Moreover, just as medical practitioners may conscientiously object to being involved in VAD,${ }^{45}$ some prospective supporters, such as community volunteers, may not wish to offer support for decisionmaking about assisted dying.

42 Medical Treatment Planning and Decisions Act 2016 (Vic) ss 31 and 34. The NSW Law Reform Commission recommends a minimum age of 16 years for a formally appointed supporter.

43 Arstein-Kerslake et al (n 13). Social isolation is increasingly recognised as a serious issue among older people: Nicholas R Nicholson, 'A Review of Social Isolation: An Important but Underassessed Condition in Older Adults' (2012) 33(2-3) Journal of Primary Prevention 137; Thomas KM Cudjoe et al, 'The Epidemiology of Social Isolation: National Health and Aging Trends Study' (2020) 75(1) The Journals of Gerontology: Series $B 107$ (reporting US survey data that approximately one quarter of older adults experience social isolation, accounting for 7.7 million Americans). As family sizes shrink and more people have few or no children, a growing number of people may reach older age without traditional family support systems: C Deindl and M Brandt, 'Support Networks of Childless Older People: Informal and Formal Support in Europe' (2017) 37(8) Ageing and Society 1543.

44 Brenda Burgen, 'Reflections on the Victorian Office of the Public Advocate Supported DecisionMaking Pilot Project' (2016) 3(2) Research and Practice in Intellectual and Developmental Disabilities $165,177$.

45 See eg, Australian Medical Association, Conscientious Objection - 2019 (Position Statement, 27 March 2019) <https://ama.com.au/position-statement/conscientious-objection-2019>. 
Attitudes and approaches to supporting the decision-making of another person may vary depending on whether the supporter is a family member or a third party, such as a disability support worker or a health or legal professional. Family members feel a stronger entitlement to be involved in decision-making and may be more paternalistic and protective. ${ }^{46}$ Supporters who are paid carers or professional advisors feel their role is to be neutral, however they report tensions between promoting individual autonomy and meeting their legal duty of care, especially for higher-risk decisions. ${ }^{47}$ Accordingly, they identify resources they need, including opportunities to talk through ethical dilemmas with colleagues or supervisors and guidelines on supported decision-making from their organisations or professional associations.

\section{The end-of-life context}

Even where support for VAD decision-making is possible in principle, barriers may exist in practice.

Legal or practical barriers to accessing support for end-of-life decisionmaking, including $\mathrm{VAD}$, could have negative impacts such as denying the seriously ill person with cognitive disability access to a service available to others and also reinforcing stigma about dying and death. The notion of a disenfranchised death has been used to describe end-of-life circumstances where a person with a cognitive or intellectual disability is socially excluded from the process of dying and deliberately excluded from the decision-making process surrounding the terminal illness. ${ }^{48}$

A recent UK interview study of people with intellectual disabilities, supporters and social care professionals found

46 Bigby, Whiteside and Douglas, (n 38).

47 Ibid; Craig Sinclair et al, 'Professionals' Views and Experiences in Supporting Decision-Making Involvement for People Living with Dementia' (2021) 20(1) Dementia 84.

48 S Read, 'Communication in the Dying Context', in S Read, ed, Palliative Care for People with Learning Disabilities (Quay Books, 2006) 93, 96, cited in Sue Read and Heather Morris, Living and Dying with Dignity: The Best Practice Guide to End-of-Life Care for People with a Learning Disability (Report, Mencap, 7 November 2008) <http://supporteddecisionmaking.com/sites/default/files/endof $\% 20$ life-care-best-practice-guide.pdf>. 
limited availability of support for more complex decisions, by which we mean decisions which may require the decision-maker to understand and process greater quantities of, or more difficult, information, or wider and/or more abstract potential effects. ${ }^{49}$

Examples included decisions about end-of-life planning and refusals of medical treatments. Moreover, '[ $\mathrm{t}$ ] he amount of support available to disabled people from frontline care professionals appeared to reduce in an inverse relationship to the complexities of the decision they needed to make'. ${ }^{50}$

Similarly, Australian stakeholders have expressed concern about people being excluded from supported decision-making arrangements when their support needs are perceived as more complex. For example, ArsteinKerslake cites comments from a participant at a University of Melbourne symposium on supported decision-making:

As is the case for supported decision-making, to date, these movements have been dominated by people with mild, as opposed to more severe cognitive disability. As articulated by one of the symposium participants 'I think we are once again leaving a whole group of people out. We've been there before. Like with [healthcare] planning. For these people it's different, and it's not easy. I don't know, perhaps they will always be in the too hard basket'. ${ }^{51}$

However, as the need for decision-making support increases, the line between supported and substituted decision-making can become blurred. A case study project in Victoria examined supported decision-making for five people with profound intellectual disability. ${ }^{52}$ One participant in the study, who 'did not use or appear to understand formal communication', developed aspiration pneumonia. His (informal) supporters, including his parents and care workers from his group home, 'were faced with assisting him with a life and death related decision', that is whether to undergo

49 Rosie Harding and Ezgi Taşcıoğlu, 'Supported Decision-Making from Theory to Practice: Implementing the Right to Enjoy Legal Capacity' (2018) 8(2) Societies 25. Fifteen disabled people, six supporters and 25 social care professionals from across England and Wales participated in the study.

50 Harding and Taşcioğlu (n 49).

51 Arstein-Kerslake et al (n 13).

52 Joanne Watson, Erin Wilson and Nick Hagiliassis, 'Supporting End of Life Decision Making: Case Studies of Relational Closeness in Supported Decision Making for People with Severe or Profound Intellectual Disability' (2017) 30(6) Journal of Applied Research in Intellectual Disabilities 1022. 
a live-saving tracheotomy procedure. While labelled supported decisionmaking, the process described reveals a substitute decision-making process guided by knowledge of the person's will and preferences:

The group spoke with Neil's medical team about his options, and spent time collaboratively weighing these up. They drew heavily from their relationships with Neil as well as his past life experiences, specifically his past experiences of tracheotomy. ... Guided by the preferences Neil had communicated [through means such as body language and vocalisations during] his past experiences ... the group collectively made the difficult decision that a tracheotomy would not be carried out. ${ }^{53}$

Changing the issue in this situation to one of accessing VAD instead of refusing a tracheotomy, the process described above would not count as a voluntary, supported decision; the supporters appear to make the decision, not assist Neil to understand his options and help him express his wishes to the doctors. This example underscores the importance of clarity about the formal and informal roles of family members, friends, care workers and others involved in the life - and death - of a person with disability.

\section{The needs of supporters}

Healthcare professionals recognise family members and others close to the patient as important supporters - either informally or potentially in a formal supporter role. At the same time, these supporters may be seen as 'second patients who could be traumatized by a patient's situation and needed special attention, care and time investment'. ${ }^{54}$ Studies have investigated the impacts of being a substitute decision-maker for a loved one in the end-of-life context and this research can identify possible stressors that formally appointed supporters may encounter. For many people, the substitute decision-making role is emotionally stressful and can generate conflicts with clinicians, as well as relatives and friends of the seriously ill person. Substitute decision-makers are troubled by uncertainty about the person's preferences and by guilt when they perceive that following the person's wishes is at odds with best interests as perceived by others. Effective communication with the person prior to loss of capacity and

\footnotetext{
53 Ibid 1031.

54 Katsiaryna Laryionava et al, 'The Second Patient? Family Members of Cancer Patients and their Role in End-of-Life Decision Making' (2018) 17(29) BMC Palliative Care 1.
} 
clinicians helps to improve substitute decision-makers' confidence in the choices they make but may not assuage guilt or reduce family conflicts. ${ }^{55}$ The negative psychosocial sequelae of substitute decision-making can be long-lasting. ${ }^{56}$

\section{The needs of clinicians}

Australian studies have revealed gaps in clinicians' knowledge of end-oflife law, including lack of knowledge of who is the lawful decision-maker for a person who lacks decisional capacity. ${ }^{57}$ With law reforms to recognise formal supporter roles, there will be a need to ensure that clinicians understand the role and responsibilities of a supporter and have the skills needed to work effectively with patients and their formal supporters. Effective practices for supported decision-making may, in fact, demand more from clinicians, a point acknowledged by the Royal Australian and New Zealand College of Psychiatrists:

The intent of SDM [supported decision-making] is not to merely shift risk and responsibility for decision-making and treatment outcomes from mental health clinicians and onto consumers, their families and carers. Instead, it places increased responsibility on clinicians to improve their way of practising in order to strengthen consumers' capacity to make decisions, whilst reducing practices viewed as coercive or manipulative. ${ }^{58}$

\section{Areas for future research}

As law reforms continue, it is important to ensure that supported decisionmaking is 'constructed, led, and continually guided by those using the support ${ }^{\text {' }}{ }^{59}$ To the extent that supported decision-making is implemented

55 Alyssa Majesko et al, 'Identifying Family Members who May Struggle in the Role of Surrogate Decision Maker' (2012) 40(8) Critical Care Medicine 2281.

56 David Wendler, 'The Theory and Practice of Surrogate Decision-Making' (2017) 47(1) Hastings Center Report, 29.

57 See Ben White et al, 'Doctors' Knowledge of the Law on Withholding and Withdrawing LifeSustaining Medical Treatment' (2014) 18(201) Medical Journal of Australia 229; Ben White et al, 'Knowledge of the Law about Withholding or Withdrawing Life-Sustaining Treatment by Intensivists and Other Specialists' (2016) 18(2) Critical Care and Resuscitation: Journal of the Australasian Academy of Critical Care Medicine, 109.

58 Royal Australian and New Zealand College of Psychiatrists, Victorian Branch, Enabling Supported Decision-Making (Position Paper, May 2018) <https://www.ranzcp.org/files/branches/ victoria/enabling-supported-decision-making-vic-branch-posi.aspx $>$.

59 Anna Arstein-Kerslake et al (n 13). 
in relation to end-of-life choices, it will be vital to understand the perspectives and experiences of those who seek support for VAD decisions, as well as the supporters.

Where VAD is legal, routine data collection should be expanded to include information on the use of supported decision-making, including the types of support used and the reasons for needing support; for example, does the person requiring support have a communication disorder or a neurocognitive illness with fluctuating or reduced capacity. A recent review of 20 years of experience of Oregon's Death with Dignity Act does not elaborate on issues related to decision-making capacity and whether those who access assisted dying have had support in their decision-making. ${ }^{60}$

The circumstances of people with specific neurocognitive disorders, such as dementia, warrant investigation. To date, the literature on access to assisted dying by people with dementia does not yet appear to address supported decision-making; for instance, on the issue of decisional capacity, a 2017 literature review concludes:

Assisted dying in dementia raises numerous questions that remain to be answered empirically. It is of major interest to determine how long the capacity to decide about one's own death is retained during the course of dementia, which factors influence this capacity and how this capacity can reliably be assessed. ${ }^{61}$

A factor that influences decisional capacity is the availability of appropriate supports and future research should investigate this topic. A recent multidisciplinary project on supported decision-making for people with dementia has started to fill the gaps in resources with a consumer guidebook and a policy development document for aged care providers. ${ }^{62}$ These materials discuss health-related decisions and advance care planning, however, $\mathrm{VAD}$ decision-making is a specific topic where future evidence-based guidance will be needed.

60 Katrina Hedberg and Craig New, 'Oregon's Death with Dignity Act: 20 Years of Experience to Inform the Debate' (2017) 167(8) Annals of Internal Medicine 579.

$61 \mathrm{~J}$ Diehl-Schmid et al, 'Suicide and Assisted Dying in Dementia: What We Know and What We Need to Know. A Narrative Literature Review’ (2017) 29(8) International Psychogeriatrics 1247.

62 Cognitive Decline Partnership Centre, 'Supported Decision-Making', The University of Sydney (Web Page) <http://sydney.edu.au/medicine/cdpc/resources/supported-decision-making.php>. 


\section{Conclusion}

In Australia, law reform is underway in the separate but potentially intersecting areas of supported decision-making and VAD. To meet their obligations under the UN Convention on the Rights of Persons with Disabilities, Australia and other signatory nations must 'ensure all citizens are considered when developing legislation, policy and practice guidelines around supported decision-making. This includes those who historically have not been invited to the self-determination "party"'. ${ }^{63}$ An analogous comment can be made about VAD, another area where self-determination is a driving principle. An important area of intersection is to consider how support for decision-making can be provided for people facing end-of-life choices, particularly older people with neurocognitive disorders such as dementia, a group that has been on the sidelines of the self-determination 'parties' both of supported decision-making and VAD.

\section{Bibliography}

\section{A Articles/books/reports}

Arstein-Kerslake, Anna et al, 'Future Directions in Supported Decision-Making' (2017) 37(1) Disability Studies Quarterly 1 doi.org/10.18061/dsq.v37i1.5070

Australian Institute of Health and Welfare, Australia's Health 2016 (Australia's Health Series No 15, Catalogue no AUS 199, 2016)

Australian Law Reform Commission, Equality, Capacity and Disability in Commonwealth Laws: Final Report (ALRC Report 124, 24 November 2014)

Australian Psychological Society, Submission to the Inquiry into End of Life Choices in the ACT (March 2018) <https://psychology.org.au/getmedia/bc8fd1fbd944-4d2e-8f64-d70445e8de5c/APS-Submission-ACT-Inquiry-into-endof-life-choices.pdf>

Beamer, Stephanie and Mark Brookes, Making Decisions: Best Practice and New Ideas for Supporting People with High Support Needs to Make Decisions (Values into Action, 2001)

63 Arstein-Kerslake et al (n 13). 
Bigby, Christine, Mary Whiteside and Jacinta Douglas, 'Providing Support for Decision Making to Adults with Intellectual Disability: Perspectives of Family Members and Workers in Disability Support Services' (2019) 44(4) Journal of Intellectual \& Developmental Disability 396 doi.org/10.3109/1366 8250.2017 .1378873

Burgen, Brenda, 'Reflections on the Victorian Office of the Public Advocate Supported Decision-Making Pilot Project' (2016) 3(2) Research and Practice in Intellectual and Developmental Disabilities 165 doi.org/10.1080/23297018. 2016.1199969

Carney, Terry and Fleur Beaupert, 'Public and Private Bricolage - Challenges Balancing Law, Services and Civil Society in Advancing CRPD Supported Decision-Making' (2013) 36(1) University of New South Wales Law Journal 175

Collins, Lauren G, Susan M Parks and Laraine Winter, 'The State of Advance Care Planning: One Decade After SUPPORT' (2006) 23(5) American Journal of Hospice and Palliative Medicine 378 doi.org/10.1177/1049909106292171

Cudjoe, Thomas KM et al, 'The Epidemiology of Social Isolation: National Health and Aging Trends Study' (2020) 75(1) The Journals of Gerontology: Series B 107 doi.org/10.1093/geronb/gby037

Deindl, C and M Brandt, 'Support Networks of Childless Older People: Informal and Formal Support in Europe' (2017) 37(8) Ageing and Society 1543 doi.org/ $10.1017 /$ S0144686X16000416

Diehl-Schmid, J et al, 'Suicide and Assisted Dying in Dementia: What We Know and What We Need to Know. A Narrative Literature Review' (2017) 29(8) International Psychogeriatrics 1247 doi.org/10.1017/s1041610217000679

Douglas, Jacinta and Christine Bigby, 'Development of an Evidence-Based Practice Framework to Guide Decision Making Support for People with Cognitive Impairment Due to Acquired Brain Injury or Intellectual Disability' (2018) 42(3) Disability and Rehabilitation 434 doi.org/10.1080/09638288. 2018.1498546

Downar, James, 'Is Physician-Assisted Death in Anyone's Best Interest?: Yes' (2015) 61(4) Canadian Family Physician 314

Downey, Lois et al, 'The Quality of Dying and Death Questionnaire (QODD): Empirical Domains and Theoretical Perspectives' (2010) 39(1) Journal of Pain and Symptom Management 9 doi.org/10.1016/j.jpainsymman.2009.05.012

Harding, Rosie and Ezgi Taşcıoğlu, 'Supported Decision-Making from Theory to Practice: Implementing the Right to Enjoy Legal Capacity' (2018) 8(2) Societies 25 doi.org/10.3390/soc8020025 
Hedberg, Katrina and Craig New, 'Oregon's Death With Dignity Act: 20 Years of Experience to Inform the Debate' (2017) 167(8) Annals of Internal Medicine 579 doi.org/10.7326/M17-2300

Joint Select Committee on End of Life Choices, Parliament of Western Australia, My Life, My Choice: The Report of the Joint Select Committee on End of Life Choices (Report No 1, August 2018)

Joint Select Committee on End of Life Choices, Submission to Parliament of Western Australia, Inquiry into the Need for Laws in Western Australia to Allow Citizens to Make Informed Decisions Regarding Their Own End of Life Choices (23 August 2018)

Laryionava, Katsiaryna et al, 'The Second Patient? Family Members of Cancer Patients and Their Role in End-of-Life Decision Making' (2018) 17(29) BMC Palliative Care 1 doi.org/10.1186/s12904-018-0288-2

Majesko, Alyssa et al, 'Identifying Family Members Who May Struggle in the Role of Surrogate Decision Maker' (2012) 40(8) Critical Care Medicine 2281 doi.org/10.1097/CCM.0b013e3182533317

Nicholson, Nicholas R, 'A Review of Social Isolation: An Important but Underassessed Condition in Older Adults' (2012) 33(2-3) Journal of Primary Prevention 137 doi.org/10.1007/s10935-012-0271-2

NSW Law Reform Commission, Review of the Guardianship Act 1987 (Report No 145, 21 May 2018)

Peisah, Carmelle, Linda Sheahan and Ben P White, 'Biggest Decision of Them All - Death and Assisted Dying: Capacity Assessments and Undue Influence Screening' (2019) 49(6) Internal Medicine Journal 792 doi.org/10.1111/ imj. 14238

Price, Annabel et al, 'Concepts of Mental Capacity for Patients Requesting Assisted Suicide: A Qualitative Analysis of Expert Evidence Presented to the Commission on Assisted Dying' (2014) 15(32) BMC Medical Ethics 1 doi.org/ 10.1186/1472-6939-15-32

Read, S, 'Communication in the Dying Context' in S Read, (ed), Palliative Care for People with Learning Disabilities (Quay Books, 2006) 93

Read, Sue and Heather Morris, Living and Dying with Dignity: The Best Practice Guide to End-of-Life Care for People with a Learning Disability (Report, Mencap, 7 November 2008) <http://supporteddecisionmaking.com/sites/ default/files/end-of\%20life-care-best-practice-guide.pdf> 
Rogers, E et al, 'Psychologists' Perspectives on Supported Decision Making in Ireland' (2020) 64(3) Journal of Intellectual Disability Research 234 doi.org/ $10.1111 /$ jir. 12712

Royal Australian and New Zealand College of Psychiatrists, Victorian Branch Committee, Enabling Supported Decision-Making (Position Paper, May 2018)

Shalowitz, David I, Elizabeth Garrett-Mayer and David Wendler, 'The Accuracy of Surrogate Decision Makers: A Systematic Review' (2006) 166(5) Archives of Internal Medicine 493 doi.org/10.1001/archinte.166.5.493

Shaw, David, Manuel Trachsel and Bernice Elger, 'Assessment of DecisionMaking Capacity in Patients Requesting Assisted Suicide' (2018) 213(1) The British Journal of Psychiatry 393 doi.org/10.1192/bjp.2018.81

Shogren, Karrie A and Michael L Wehmeyer, 'A Framework for Research and Intervention Design in Supported Decision-Making' (2015) 3(1) Inclusion 17 doi.org/10.1352/2326-6988-3.1.17

Sinclair, Craig et al, 'Professionals' Views and Experiences in Supporting Decision-Making Involvement for People Living with Dementia' (2021) 20(1) Dementia 84 doi.org/10.1177/1471301219864849

St Godard, Edward (Ted), 'Is Physician-Assisted Death in Anyone's Best Interest?: No' (2015) 61(4) Canadian Family Physician 316

Watson, Joanne, Erin Wilson and Nick Hagiliassis, 'Supporting End of Life Decision Making: Case Studies of Relational Closeness in Supported Decision Making for People with Severe or Profound Intellectual Disability' (2017) 30(6) Journal of Applied Research in Intellectual Disabilities 1022 doi.org/10.1111/jar.12393

Wendler, David, 'The Theory and Practice of Surrogate Decision-Making' (2017) 47(1) Hastings Center Report 29 doi.org/10.1002/hast.671

White, Ben and Lindy Willmott, 'Future of Assisted Dying Reform in Australia' (2018) 42(6) Australian Health Review 616 doi.org/10.1071/AH18199

White, Ben et al, 'Doctors' Knowledge of the Law on Withholding and Withdrawing Life-Sustaining Medical Treatment' (2014) 201(4) Medical Journal of Australia 229 doi.org/10.5694/mja13.00217

White, Ben et al, 'Knowledge of the Law about Withholding or Withdrawing Life-Sustaining Treatment by Intensivists and Other Specialists' (2016) 18(2) Critical Care and Resuscitation: Journal of the Australasian Academy of Critical Care Medicine 109 


\section{B Legislation}

End of Life Choices (Voluntary Assisted Dying) Bill 2020 (Tas)

Medical Treatment Planning and Decisions Act 2016 (Vic)

Powers of Attorney Act 2014 (Vic)

Voluntary Assisted Dying Act 2017 (Vic)

Voluntary Assisted Dying Act 2019 (WA)

\section{Treaties}

Convention on the Rights of Persons with Disabilities, opened for signature 13 December 2006, 2515 UNTS 3 (entered into force 3 May 2008)

\section{Other}

Australia Bureau of Statistics, 'Dementia and Death in Australia', Causes of Death, Australia, 2015 (Catalogue No 3303.0, 26 July 2017) <https://www.abs. gov.au/ausstats/abs@.nsf/Lookup/by\%20Subject/3303.0 2015-Main\%20 Features-Dementia -10002>

Australia Bureau of Statistics, 'Stroke', Profiles of Disability, Australia, 2009 (Catalogue No 4429.0, 27 June 2012) <https:/www.abs.gov.au/ausstats/ abs@.nsf/Lookup/4429.0main+features100262009>

Australian Medical Association, Conscientious Objection - 2019 (Position Statement, 27 March 2019) <https://ama.com.au/position-statement/ conscientious-objection-2019>

Cognitive Decline Partnership Centre, 'Supported Decision-Making', The University of Sydney (Web Page) <https://cdpc.sydney.edu.au/research/ planning-decision-making-and-risk/supported-decision-making/>

'Dementia', Australian Institute of Health and Welfare (Web Page) <https://www. aihw.gov.au/reports-data/health-conditions-disability-deaths/dementia/ overview>

'Enduring Power of Attorney', Office of the Public Advocate (Web Page) <http:// www.publicadvocate.vic.gov.au/power-of-attorney/supportive-attorneyappointments>

NSW Disability Network Forum, Submission GA39 to NSW Law Reform Commission, Review of the Guardianship Act 1987 (25 January 2017) 
Royal Australian and New Zealand College of Psychiatrists NSW Branch, Submission GA53 to NSW Law Reform Commission, Review of the Guardianship Act 1987 (31 January 2017)

Seniors Rights Service, Submission GA61 to NSW Law Reform Commission, Review of the Guardianship Act 1987 (31 January 2017) 
This text is taken from Voluntary Assisted Dying: Law? Health? Justice?, edited by Daniel J Fleming and David J Carter, published 2022 by ANU Press, The Australian National University, Canberra, Australia.

doi.org/10.22459/VAD.2022.03 